\title{
La Revolució Francesa i el Terror. Perspectives actuals des de la història social i cultural
}

\author{
Santiago Quiles Verdú \\ quiles_san@gva.es \\ IES José Marhuenda Prats \\ Carrer del Príncep d'Astúries, 18 \\ 03650, El Pinós, Alacant
}

Resum: El període del Terror de la Revolució Francesa ha estat en la historiografia revolucionària objecte de les més diverses anàlisis, les quals, en molts casos, han servit com a element clau per a interpretar i valorar tot el procés. Aquest treball se situa en aquesta línia en analitzar els orígens intellectuals de la Revolució, la figura de Robespierre i el període del Terror. La perspectiva emprada és la de la història social i cultural i ens porta, per una banda, a concloure que cal fugir de les explicacions deterministes, materialistes $\mathrm{i}$ idealistes, $\mathrm{i}$ cal introduir els contextos concrets, la contingència i la decisió individual com a factors explicatius, i, per l'altra, a assenyalar com una mancança dels autors i les autores que analitzem, en concret, l'absència o la poca importància causal que té, a l'hora d'explicar l'acció revolucionària, el conflicte entre la llibertat republicana i el dret de propietat, això és, entre el projecte jacobí robespierrista i el liberalisme doctrinari.

Paraules clau: idees illlustrades, Robespierre, Terror, democràcia, revisionisme.

\section{The French Revolution and The Terror. \\ Current perspectives from social and cultural history}

Авsтract: The Terror of the French Revolution has been the subject of many analyses in the historiography and, in many cases, these have served as key elements in interpreting and evaluating the whole process. This work takes the same focus, analysing the intellectual origins of the Revolu- 
tion, the figure of Robespierre, and the period of The Terror. The approach is one of social and cultural history, and leads us to conclude that determinist, materialist and idealist explanations must be avoided and that specific contexts, contingencies, and individual decisions must be considered as decisive factors; and also to indicate that the authors we analyse present a weakness in their analyses, namely the absence of or scant importance given to the conflict between republican freedom and the right of property, that is, between the Robespierrist Jacobin project and doctrinaire liberalism, in explaining the revolutionary events.

KeYwords: Enlightenment, Robespierre, Terror, democracy, revisionism.

\section{Introducció}

La historiografia de la Revolució Francesa es pot dividir en dos corrents interpretatius en pugna. Per a la interpretació clàssica o social, hegemònica fins a la segona meitat del segle xx, és l'esdeveniment amb el qual la burgesia reemplaça la classe aristocràtica dirigent. Per a la interpretació liberal, hegemònica en l'últim quart del segle xx, hauria estat una revolució política derivada de la popularització de les idees illlustrades i de la manipulació de les masses populars per part d'una elit més o menys homogènia. ${ }^{\mathrm{T}}$

En la historiografia republicana del segle xIx i en autors com, per exemple, A. de Tocqueville, F. Guizot, A. Thierry, A. Thiers, F. A. Mignet i Victor Cousin, hi ha un predomini de la tesi de la naturalesa social de la revolució. Com afirma Hobsbawm, «tal como el propio Marx admitió abiertamente, de estos hombres fue de dónde

I Dues obres importants que analitzen la historiografia de la Revolució són Eric Hoвsвawm, Los ecos de la marsellesa, Barcelona, Crítica, I99i, i Neil Davidson, Transformar el mundo, Barcelona, Pasado y Presente, 2013. 
sacó la idea de la lucha de clases en la historia». ${ }^{2}$ Ja des de l'acadèmia, a partir de la segona meitat del segle XIX, trobem com a historiadors més reeixits d'aquest corrent F. A. Aulard, A. Mathiez, G. Lefebvre i E. Labrousse. Finalment, com a representants pròpiament marxistes, i protagonistes de la discussió amb els historiadors liberals de la segona meitat del segle xx, són essencials A. Soboul i M. Vovelle. Aquest sumari d'autors mostra la preponderància de la interpretació social fins a la segona meitat del segle xx.

El gran atac a la perspectiva social es produeix als anys cinquanta del segle xx amb The myth of the French Revolution (1955), d'Alfred Cobban. La revolució és política, no es pot defensar la distinció entre noblesa i burgesia. No hi ha lluita de classes. L'èxit d'aquest corrent revisionista hagué d'esperar, però, fins a la publicació de Penser la Révolution Française (1978), de F. Furet. La Revolució, lluny de ser l'escenari de la lluita de classes, ho va ser d'una ideologia de democràcia directa, igualitarisme i voluntat general que substituïa allò social per allò polític: «de una explicación social con consecuencias políticas a una revolución política con consecuencias sociales. [Una] reconceptualización de la revolución a través de una vuelta a la historiografía del siglo XIX, en especial a las obras de Burke, Tocqueville, Quinet y Cochin».3

En l'actualitat, si bé podem diferenciar entre aquests dos corrents, la matisació de les posicions, l'adopció de diverses perspectives epistemològiques i l'augment dels temes tractats tenen com a resultat un debat complex amb aportacions constants en un evident renaixement de la historiografia revolucionària. ${ }^{4}$ Així mateix, aquest interés trans-

2 Eric Новsваwм, Los ecos de la Marsellesa, p. 27.

3 Neil Davidson, Transformar el mundo, p. 515.

4 Les aportacions de la historiografia en els darrers anys consisteixen, per una banda i a tall d'exemple, en la resignificació d'alguns debats com ara el Terror, Robespierre o la continuïtat amb l'Antic Règim en relació amb les celebracions per a legitimar el nou regim; per altra banda, en la constitució (o aprofundiment) de nous objectes d'investigació, com 
cendeix la ciència històrica i es projecta als àmbits cultural i polític. La negativa de l'Ajuntament de París a dedicar un carrer a Robespierre l'any 20 II $^{5}$ o l'èxit de la novel.la 14 de juliol, ${ }^{6}$ en són mostres.

Si la discussió historiogràfica transcendeix la qüestió acadèmica és perquè de la posició que s'hi adopte sobre el fet revolucionarise segueix una determinada acció política. Si revolució és igual a terror i els canvis que provoca són mínims, ${ }^{7}$ inexistents o negatius, les revolucions s'han de evitar. Si, per contra, una revolució pot capgirar la història en una direcció emancipadora, les revolucions són desitjables. La citació següent exemplifica el que diem:

ara la consideració de la Revolució Francesa en el si d'un procés global revolucionari, la influència de la cultura clàssica en el republicanisme o els orígens anglosaxons dels jacobins, entre d'altres. Un mapa per a guiar-se en la ingent producció dels darrers vint-i-cinc anys el configuren els articles següents: Mercedes VÁzQUEZ DE PRADA, «A vueltas con la revolución francesa. Viejos debates y nuevas propuestas", Historia Contemporánea, n. 51, 2013, pp. 50954I, i Álvaro SANTANA ACUÑA, «Entre la cultura, el lenguaje, lo social y los actores: la nueva historiografía anglófona sobre la Revolución Francesa», Historia Social, n. 54, 2006, pp. I57-I8I. Així mateix, trobem David ANDREss, «Introduction: Revolutionary historiography, adrift or at large? The paradigmatic quest versus the exploration of experience», dins David Andress (ed.), Introduction to experiencing the French Revolution. Oxford, Voltaire Foundation, 20I3, pp. I-I5. Es tracta d'un comentari crític molt aclaridor estructurat al voltant de les mancances explicatives de la nova historiografia centrada en l'experiència individual (emocions, percepcions, sentiments). Aquesta perspectiva comporta la dificultat de comprendre les accions més enllà de contextos molt concrets i la resposta consegüent de part de la historiografia actual sobre la necessitat de recuperar o produir un paradigma estructural o ideològic que faça possible una interpretació del procés revolucionari en el seu conjunt, que incorpore les accions individuals en un tot coherent.

5 Una calle para Robespierre en París: www.sinpermiso.info/textos/una-calle-para-robespierre-en-la-capital (consultat el 27/2/2020).

6 Éric Vuillard, 14 de juliol, Barcelona, Edicions 62, 20I7. L'edició original francesa és del 2016.

7 Trobem una caracterització sintètica del corrent revisionista en Peter McPHeE, La Revolución Francesa. 1789-1799, Barcelona, Crítica, 2007, pp. 215-220. El corrent liberal o revisionisme és minimalista perquè la revolució no hauria produït canvis o haurien estat mínims o, fins i tot, els hauria endarrerit.

Cercles. Revista d'Història Cultural, 23 (2020), 19-55.

ISSN: 1139-0158. e-ISSN: 1699-7468. DOI: 10.1344/cercles2020.23.1009. 
Si se puede mostrar que todo lo que existe ahora es resultado de una «revolución» reciente, entonces es más fácil pensar en cambiar las actuales instituciones. Lo que existe a nuestro alrededor puede verse como una creación artificial, casi accidental. Es parte de la cultura, no de la naturaleza. Si el sistema familiar o la ética capitalista solo existen desde hace unos pocos siglos, es más fácil creer que tampoco puede durar mucho tiempo. La visión de numerosas revoluciones en el reciente pasado es esencialmente optimista, utópica. Las premisas de la continuidad pueden por el contrario resultar más atractivas para quienes desean preservar los valores duraderos y les disgustan los cambios profundos..$^{8}$ (Alan Macfarlane)

Des d'aquest enfocament polític i d'acord amb, entre molts d'altres, McPhee, Davidson o Hobsbawm, el revisionisme és, sobretot, un component més de la lluita ideològica que engegà el neoliberalisme contra l'estat del benestar i contra la possibilitat, parafrasejant el títol del llibre de Davidson, de transformar el món. És aquesta relació entre acadèmia i context cultural (la història com un camp de batalla cultural, com un element més del debat polític) la principal raó per la qual hem triat el tres debats que analitzarem tot seguit amb una certa profunditat:

a) Depenent de com s'entenga la recepció de les idees il.lustrades, es podrà defensar, es podrà posar l'accent, en el caràcter social o ideològic de la revolució. ¿La revolució és el producte de la manipulació de les elits intel.lectuals sobre les masses, o les masses es converteixen en subjecte revolucionari com a efecte no només de les idees il.lustrades, sinó de les condicions socials, econòmiques i culturals de finals del segle XviII?

8 Citat per Neil Davidson, Transformar el mundo, p. 5I8. 
b) ¿És el Terror l'acte de quelcom que ja hi era en potència en forma d'idees des del principi de la Revolució, és a dir, des del I789 amb més nombre de víctimes?, ¿o és una necessitat per a salvar la Revolució en un context extraordinàriament complex de guerra civil, guerra internacional, lògiques conspiradores i pressió popular? Aquest debat és fonamental perquè part de l'acadèmia i la cultura popular identifica el Terror amb la Revolució, i utilitza aquesta identificació per a deslegitimar el fet revolucionaricom a instrument per al canvi social i econòmic.

c) Robespierre: símbol del Terror i encarnació del mal per a part de la historiografia' i per a l'opinió popular. Per una banda, haurem de veure què té a veure aquesta imatge amb la realitat $i$, per l'altra, si no hi té res a veure, caldrà analitzar les raons de l'interés de situar Robespierre fora de la humanitat. ¿̇́s més violent que altres revolucionaris o és un individu ordinari en circumstàncies extraordinàries? Des d'una perspectiva democràtica, on l'hauríem de situar?

\section{Els orígens intel.lectuals de la Revolució Francesa}

Aquest debat se centra en el paper que les idees illustrades (i clàssiques) tingueren en l'inici i el desenvolupament de la Revolució Francesa. Són les idees illustrades la causa principal de la Revolució?, quin és el procés mitjançant el qual les idees de les elits illustrades s'estenen pels caps de les classes populars?, com es difonen els llibres i quina importància tenen en la creació de subjectes revolucionaris?,

9 A hores d'ara i tenint en compte la historiografia dels últims vint anys, pot semblar que aquesta imatge ha estat superada. Malauradament no és així. Un exemple reeixit, com veurem de seguida, en el manteniment de la llegenda negra és el de les obres de Jonathan Israel: Robespierre és un colpista megalòman, àvid de poder i antítesi de la democràcia. En l'opinió popular, la imatge negra de Robespierre és hegemònica.

Cercles. Revista d'Història Cultural, 23 (2020), 19-55.

ISSN: 1139-0158. e-ISSN: 1699-7468. DOI: 10.1344/cercles2020.23.1009. 
com es transforma una idea en acció revolucionària? Aquestes preguntes (d'impossible resposta definitiva) poden servir com a exemples dels problemes que es tracten en aquest debat. Només, però, podem aspirar a fer interpretacions tan acurades com siga possible que incloguen el coneixement significatiu, històric o d'altres especialitats que en tenim. A continuació intentarem mostrar aquest debat amb una certa complexitat i farem referència, primer, als seus inicis i a les tesis de Jonathan Israel i, després, a les idees, sobretot, de R. Chartier, R. Darnton i M. Linton.

\section{La tesi clàssica, Chartier i Darnton}

La tesi clàssica afirma que la lectura té el poder de modelar les subjectivitats: la Revolució va ser possible perquè un exèrcit de lectors passius va patir una transformació ideològica arran de les lectures illustrades. Com afirma Chartier fent referència a les obres de Tocqueville, Taine i Mornet, trobem un patró d'interpretació la síntesi del qual seria aquesta: «si los franceses de finales del siglo XvIII hicieron la Revolución es porque, previamente, habían sido transformados, hechos, por los libros». ${ }^{\text {IO }}$

Aquesta tesi, matisada, és defensada en l'actualitat per autors com J. Israel: ${ }^{\text {II }}$ «el surgimiento, crecimiento y difusión de la Ilustra-

Io Roger Chartier, Espacio público, crítica y desacralización en el siglo XVIII. Los origenes culturales de la Revolución Francesa, Barcelona, Gedisa, 1995, pp. 8I-82. Tanmateix, els hàbits lectors, l'abandó gradual de les temàtiques religioses, l'augment de l'alfabetització i la producció editorial permeten plantejar, matisada, la hipòtesi del poder causal dels llibres.

II Altres, com Keith BaKer, Inventing the French Revolution, Cambridge, Cambridge University Press, 1990, encara que matisada amb l'ús del concepte de discurs de Foucault, també segueixen en gran mesura, com veurem després, una versió de la tesi clàssica. Una defensa de les seues tesis contra els seus crítics la trobem en Keith BAKER, "El concepto de cultura política en la reciente historiografía de la Revolución Francesa», Ayer, n. 62, 2006, pp. 89-IIO. 
ción radical [...] puede decirse que es con mucho el factor principal de cualquier comprensión adecuada de cómo y por qué la Revolución se desarrolló como lo hizo». ${ }^{\mathrm{I} 2}$ Per a Israel, la Il.lustració és un moviment unitari en el si del qual hi ha una lluita entre radicals -republicans i demòcrates seguidors de la filosofia de Spinoza que engeguen un atac sistemàtic contra l'autoritat i creen un nou règim polític i social — i moderats — reformistes institucionals però defensors dels privilegis i, per tant, enemics de la democràcia (Descartes, Newton, Leibniz, Locke, Hume o Voltaire en serien exemples)—. Fora de l'esquema trobem els enemics de la raó: reaccionaris com De Maistre i populistes autoritaris que Israel identifica amb Rousseau, els jacobins i Robespierre. ${ }^{13}$ En altres paraules, hi va haver una vertadera revolució a favor de l'emancipació humana, identificada amb la política dels girondins, i dues pseudorevolucions: la monarquia constitucional En la historiografia cultural trobem una superació de la tesi clàssica en autors com i la Convenció jacobina.

En la historiografia cultural trobem una superació de la tesi clàssica en autors com Chartier i Darnton. La tesi de Chartier és la següent: «Si existe algún vínculo entre la difusión masiva de la litera-

I2 Jonathan IsRael, Una revolución de la mente. La ilustración radical y los orígenes intelectuales de la democracia moderna, Pamplona, Laetoli, 2015 , p. 193.

I3 Com quedarà clar en les conclusions arran de l'anàlisi dels tres debats, aquesta valoració d'Israel no resisteix la mínima comparació amb els fets. Considerar 1791 i i795 els períodes més democràtics quan en ambdós casos s’actua contra la Declaració de I789, és insostenible. Com veurem, si es pot qualificar de democràtic algun període de la revolució, és el període de la Convenció jacobina. Trobem una anàlisi crítica de l'obra d'Israel, per exemple, en Pablo Facundo Escalante, «Revolutionary Ideas. An Intellectual History of the French Revolution from The Rights of Man to Robespierre», Prohistoria, n. 2I, generjuny 20I4, Pp. 20I-207; en Minchul KIM, «Revolutionary Ideas: An Intellectual History of the French Revolution from the Rights of Man to Robespierre», History of European Ideas, n. 4I, 20I5, pp. 825-830; en José ÁlvVAReZ Junco, «Rousseau y la Ilustración», Revista de Libros, n. I84, 20I2, www.revistadelibros.com/articulos/rousseau-y-la-ilustracion (consultat el 9/6/2020), o en Francesco Benigno, «Never the Same Again. On Some Recent Interpretations of the French Revolution", Annales (ed. angl.), n. 7I, juny 20I6, pp. 187-221.

Cercles. Revista d'Història Cultural, 23 (2020), 19-55.

ISSN: 1139-0158. e-ISSN: 1699-7468. DOI: 10.1344/cercles2020.23.1009. 
tura panfletaria de una agresividad irrespetuosa y la destrucción de la monarquía no es ni directo ni obligado». ${ }^{14}$ La distribució restringida a determinades zones, la dificultat de les obres, l'interés efímer, la incredulitat del públic, que considerava les obres un mer divertiment, i la impossibilitat d'afirmar que l'interés per les mateixes lectures implicaria una comunitat d'opció ideològica i d'acció, són els arguments que sostenen la tesi..$^{\text {Is }}$ Així mateix, afirma que, amb les mateixes lectures, la posició respecte del procés revolucionari depenia de la posició social que s'ocupava, això és, dels interessos de classe. Sent així, el poder causal dels llibres, si més no, s'ha de relativitzar.

Per a Darnton, en canvi, més enllà dels interessos dels uns i dels altres, el règim no tenia ja cap legitimitat: «Perdieron la fe en el régimen [aquells que gaudien de privilegis] antes de que éste cayera y más adelante se dieron cuenta de que tenían bastante más que perder. Pero en lugar de congregarse alrededor del viejo orden, por lo general se sumaron a su destrucción». ${ }^{16}$ Els «llibres filosòfics» eren essencials per a comprendre per què el règim va perdre la legitimitat, per a comprendre per què «van perdre la fe». ${ }^{17}$ Així mateix, Darnton reivindica el poder de la literatura per a canviar les vides amb el fet que havia estat un dels dispositius per a legitimar la monarquia des de Lluís XIV ${ }^{18}$ Les experiències dels lectors sobre les seues lectures i el fet que les autoritats es preocuparen de prohibir-les i perseguir-les, «señalan en la misma dirección: los lectores se tomaban en serio la literatura prohibida». ${ }^{19}$

I4 Roger Chartier, Espacio público, crítica y desacralización, p. 97.

I5 Ibídem, pp. 96-99.

I6 Robert DARnton, Los best sellers prohibidos en Francia antes de la revolución, Buenos Aires, FCE, 2008, pp. 293-294.

I7 Ibídem, p. 288.

I8 Ibídem, p. 296.

I9 Ibídem, pp. 336-339.

Cercles. Revista d'Història Cultural, 23 (2020), 19-55. ISSN: 1139-0158. e-ISSN: 1699-7468. DOI: 10.1344/cercles2020.23.1009. 
Les obres d'aquests autors, més enllà del grau d'importància que els adjudiquen, relativitzen la potència transformadora de les lectures illustrades i la converteixen en una variable més: la recepció de les idees i les accions que impliquen, en els casos que ho facen, depenen d'una infinitat de variables. Les seues obres cerquen l'origen de la Revolució en variables de caire cultural i, en menor manera, socials. Les tesis de Furet o Baker (sobre les quals parlarem) no explicarien el pas de la idea a l'acció. ${ }^{20}$

\section{Els usos dels discursos}

Una de les historiadores actuals que introdueix major complexitat en l'explicació dels orígens de la Revolució és M. Linton. El punt de partida és la crítica de les tesis de Keith Baker. Per a aquest autor, hi havia tres discursos en pugna (raó, justícia i voluntat) que van estructurar el segle XVIII, fins a la victòria l'any 1789 del discurs rousseaunià de la voluntat. Tal reducció és, per a Linton, fer història sense referència als esdeveniments, de manera que la història roman reduïda a lluites de conceptes en un cel platònic en què els individus no passen de ser mers instruments de les idees: «the danger is that if do not separate the two phenomena - Revolution an ideas before the Revolution - we will fall into the trap of attributing the former to the latter — and no such easy connection exists». ${ }^{21}$ La Revolució, així, seria una revolució lingüística. ${ }^{22}$ Contra aquesta simplificació, destaquem tres qüestions de Linton: la introducció, pròpia de la historio-

20 Ibídem, pp. 263-27I.

2I Marisa Linton, "The intellectual origins of the French Revolution», dins P. CAMPBell, The origins of the French Revolution, Basingstoke (UK), Palgrave Macmillan, 2005, pp. I39-159.

22 Mercedes VÁzquez de Prada, «A vueltas con la revolución francesa», p. 52I.

Cercles. Revista d'Història Cultural, 23 (2020), 19-55.

ISSN: 1139-0158. e-ISSN: 1699-7468. DOI: 10.1344/cercles2020.23.1009. 
grafia social, dels contextos específics; la sofisticació del concepte de discurs en retroalimentar-lo amb els contextos i els individus; i la demostració, amb l'anàlisi de la virtut, la impossibilitat de reduir els processos històrics a idees.

En aquest sentit, contra la reducció de les idees a una crítica aristocràtica que faria Darnton, s'ha d'ampliar el focus i parlar d'una cultura comuna de les classes educades independentment dels seus orígens socials, això és, afirmar que compartien una sèrie de conceptes amb els quals pensaven la realitat i que, depenent dels contextos socials i culturals, es traduirien en unes o altres accions concretes. La importància d'això és que la mateixa existència d'una cultura comuna de les classes educades és en si mateixa un argument contra les tradicions de sang i de naixement, contra els privilegis. En altres paraules, aquesta cultura comuna era potencialment revolucionària (es va convertir en acte revolucionari el I789). Un exemple, segurament el de més potència revolucionària, és el concepte de dret natural. El fonament de la Declaració de 1789 i de la jacobina de 1793 sanciona l'existència de drets prepolítics fundats en la naturalesa humana. Les diferències entre individus, les jerarquies socials, en definitiva, les desigualtats econòmiques i culturals, són contingències històriques. ${ }^{23}$ Una desnaturalització de la realitat social amb evidents potencialitats transformadores.

El que s'ha de veure, per tant, és com s'entenien els conceptes potencialment revolucionaris al llarg del segle XVIII i, sobretot, com funcionaven en els contextos concrets i en la seua relació amb el poder. En Inventing the French Revolution (1990), Baker introdueix les idees en el context específic des de l'anàlisi foucaultiana del dis-

23 Com veurem, sobretot en la conclusió i sota el guiatge de Florence Gauthier, contra la idea que la Revolució Francesa fou una revolució burgesa, si ens fixem en el període jacobí i en les declaracions de drets de 1789 i de I793, hauríem de parlar de revolucions dels drets humans. 
curs, això és, assumint que el significat depén d'una determinada relació de poder, d'un règim de veritat justificat pel saber. Linton defensa que no es poden reduir els discursos a tres i que les idees no són mòmies, sinó elements vius, dinàmics, que depenen de l'individu, de la classe social, del moment cultural i material concret. És tenint en compte tot plegat que podem concloure si una idea es convertirà en una acció o en una altra. Llegint Baker, diu Linton, "One has the impression at times of the tail (the discourse) wagging the dog (the person who speaks the discourse)». ${ }^{24}$

Hi ha en Linton, com veiem, una ampliació de la concepció del llenguatge. En concret, el llenguatge és un discurs, una ideologia i una estratègia retòrica. És un discurs perquè és un conjunt de paraules mitjançant el qual un usuari guanya autoritat i poder, $i$, depenent de l'usuari, el significat i les conseqüències del seu ús variaran: el discurs de la nació es pot utilitzar per a anar a la guerra o per a defensar la igualtat. És una ideologia, és a dir, un conjunt de creences conscients en defensa d'una determinada postura política. Nació o pàtria com a discurs es concretaven d'una manera o d'una altra en ideologies específiques i rivals. I és també una estratègia retòrica: per què s'usa aquest discurs i no un altre?, quina és la intenció de qui parla?, en quin context parla?, de quin context cultural forma part?

Un exemple del que diem és el concepte de virtut, que no té en compte Baker i que Linton utilitza com a exemple metodològic per a investigar altres discursos. La virtut era la dedicació a l'interés públic contra l'interés personal. A principis del segle XviIr hi havia tres discursos de la virtut en competència. La monarquia virtuosa: la virtut és del rei, que assegura el benestar del poble; la virtut noble: naixement, habilitat militar, valentia i valor farien els nobles ideals per a ser alts funcionaris de l'Estat; la virtut cívica (d'arrel grecoromana): tots els individus podien ser subjectes virtuosos i podien de-

24 Marisa Linton, «The intellectual origins of the French Revolution», p. I55.

Cercles. Revista d'Història Cultural, 23 (2020), 19-55.

ISSN: 1139-0158. e-ISSN: 1699-7468. DOI: 10.1344/cercles2020.23.1009. 
fensar els seus drets polítics des de la virtut. A la meitat del segle XviII se n'hi afegí un més, el de la virtut natural, que, com el de la virtut cívica, tendia a l'igualitarisme. La virtut natural, comparada amb la virtut cívica, que tenia fonament polític, es basava en sentiments d'humanitat compartits, que portaven a l'ajuda mútua i al desig de garantir la felicitat de tots els ciutadans.

Aquesta manera de comprendre el llenguatge li permet a Linton oposar-se a la tesi de Furet segons la qual el I789 és el moment de la invenció d'un nou discurs que juxtaposa política i moralitat i desemboca en el Terror. Moral i política estaven unides ja durant tot el segle XviII. Si el discurs de la virtut cívica es converteix en una ideologia que justifica el Terror, hem de veure per què, $i$ ho hem de veure, sí, en el mateix discurs, però també en un context polític i social canviant, en la guerra interna o en la guerra internacional. El que ens demostra Linton no és que el discurs de la virtut va ser la causa principal de la Revolució, sinó que, amb d'altres, és necessari per tal d'explicar els orígens de la Revolució.

El discurs de la virtut va ser durant tot el segle XviII potencialment revolucionari, però es convertí en acció revolucionària a partir de I789, i els desenvolupaments del procés feren que es convertira el I793 en la base del Terror. Fins a aquest moment havia estat un conjunt d'arguments per a criticar l'Antic Règim, no per a engegar una política real, la qual cosa ocorregué en circumstàncies concretes extraordinàries al si d'un procés igual d'extraordinari. ${ }^{25}$ Aquesta tesi és la ja clàssica de Tackett: la violència revolucionària només es pot explicar en el context de guerra civil i internacional, pressió de les classes populars, context conspirador i l'aparició subsegüent del pànic. ${ }^{26}$ En definitiva, la transformació del discurs en acció, siga el de

25 Marisa Linton, «The intellectual origins of the French Revolution», p. I59.

26 Vegeu Timothy Tackett, Becoming a Revolutionary. The Deputies of the French National Assembly and the Emergence of a Revolutionary Culture (1789-1790), Princeton, 
la virtut o el del dret natural, depén de nombroses variables alienes al discurs, no d'una estranya immanència que converteix mecànicament les idees en accions.

En conclusió, sense fer referència a les idees illustrades no podem comprendre la Revolució, però les idees ni impliquen necessàriament accions ni determinen un tipus concret d'acció. Cal connectar-les als contextos $\mathrm{i}$ individus específics per tal de veure com es manifesten És el que farem tot seguit per a analitzar el Terror en el període jacobí de la Convenció, un període de moralització estructurat per la virtut.

\section{El Terror}

Ens centrarem en el període jacobí de la Convenció, des del juny de I793 fins al juliol de 1794, amb la conspiració del 9 de termidor i l'execució de Robespierre i un centenar de jacobins més. ${ }^{27}$ Aquest període representa, en síntesi, l'adopció de mesures extraordinàries en un context extraordinari, en paraules de Robespierre: «el terror

Princeton University Press, 1996, i Timothy TACKeTt, El Terror en la Revolución Francesa, Barcelona, Pasado \& Presente, 20I5. Vegeu una crítica a Tackett a Keith BAKER, «El concepto de cultura política», pp. IO2-IO3, on sosté que la concepció de Tackett menysprea les idees polítiques fins a tal punt que el procés revolucionari és un procés psicosocial.

27 Ens centrem aquí en les accions dels revolucionaris en la fase de la Revolució que la historiografia ha anomenant Terror tot $\mathrm{i}$ ser conscients que les investigacions dels darrers anys no permeten situar l'origen de les mesures terroristes en aquest segment temporal i van més enllà de la tesi de Tackett que les situa en Varennes, en la fugida del rei. Les investigacions de M. Ozouf o P. Gueniffey en són un exemple: es poden resseguir les mesures que s'institucionalitzaren entre 1793 i 1794 (eliminació de la separació entre el poder legislatiu i l'executiu, censura, detencions arbitràries, confiscació de correspondència, etc.) el mateix juliol de 1789. Trobem una anàlisi de la qüestió en M. Betlem Castellà i Pujols, «Les comités des rapports et des recherches: aux origines de la terreur?», Trienio, n. 67, maig 2016, pp. 35-67.

Cercles. Revista d'Història Cultural, 23 (2020), 19-55.

ISSN: 1139-0158. e-ISSN: 1699-7468. DOI: 10.1344/cercles2020.23.1009. 
no és més que la justícia ràpida, severa i inflexible». ${ }^{28}$ Dues lleis remarquem per tal de fer-nos-en una idea: la Llei de sospitosos del 17 de setembre de 1793 definia la categoria de sospitós de manera tan general que en la pràctica atorgava la possibilitat de detenir a qualsevol persona; i la Llei del 22 de pradial admetia només un resum de les proves, abolia els consells de defensa, els testimonis de la defensa no podien assistir als judicis i les condemnes eren d'absolució o de mort. Una xifra per a fer-nos conscients de la magnitud: en la rebel.lió contrarevolucionària de la Vendée, les xifres de morts estan al voltant de 250.000 insurgents i 200.000 republicans; i entre París i la resta del territori francès foren sentenciades pel Tribunal de la Revolució unes 17.000 persones. ${ }^{29}$

Si això anterior és el què, el per què inclou diverses raons: l'oposició a la revolució que, ja activa l'any I789, s'havia intensificat durant el període I79I-I793; les insurreccions federalistes contra el centralisme jacobí; la novetat de la situació i l'absència, per tant, de models d'acció en què basar-se; la pressió de les classes populars; la

28 En la línia del que acabem d'apuntar en la nota anterior, vegeu Michel BiARD, «Remplacer la Terreur par la "terreur" pour mieux comprendre l'une et l'autre», H-France Salon, n. II, issue I6/3, 20I9, pp. I-IO. Biard defensa que el Terror no fou un sistema polític limitat en un període cronològic. Aquesta és la versió termidoriana que ens hem cregut durant dos segles i que hauria impedit estudiar el Terror de manera acurada: «Il ne s'agit point ici, répétons-le une nouvelle fois, de chercher des "excuses" ou d'atténuer les horreurs insupportables de certaines répressions, mais de se donner les moyens d'appréhender la complexité de la terreur au prisme de l'extraordinaire» (p. 7). Així mateix, no es pot parlar de sistema del terror, de dictadura jacobina, si tenim en compte el caràcter temporal de les mesures i el reconeixement del caràcter extraordinari del govern: «D'autre part et surtout, l'application de la Constitution a été suspendue en raison du caractère extraordinaire reconnu au gouvernement, pour autant, jamais ses dispositions n'ont été remplacées par les mesures extraordinaires, de la même manière que cette suspension fut conçue comme temporaire et ne fit donc point de la Convention un pouvoir redevenu constituant» (p. 8).

29 Marisa Linton, «Terror and politics», dins D. Andress (ed.), The Oxford Handbook of the French Revolution, Oxford (UK), Oxford University Press, 20I5, pp. 471-486. 
guerra contra les potències estrangeres, que va fer necessària una economia de guerra dirigida per una assemblea legislativa derivada de la fugida del rei. Tot plegat implicava una radicalització de l'ambient conspirador i una situació estructuralment inestable. ${ }^{30}$ Les mesures havien de ser necessàriament extraordinàries.

\section{Guerra}

Les derrotes durant els primers mesos de la guerra (el 20 d'abril de I792 França declara la guerra a Àustria) i el descrèdit del rei derivat de l'intent de fugida i de la destitució dels ministres girondins el I3 de juny de 1792, van potenciar un context explosiu: el rei va ser acusat de conspirar contra França i els parisencs van prendre el palau de les Tulleries el ıo d'agost $i$, com a conseqüència de la notícia que els prussians havien pres Verdun el 2 de setembre de 1792, el poble revolucionari engegà tribunals populars que sentenciaren a mort prop de mil dos-cents presos. ${ }^{3 \mathrm{~L}} \mathrm{La}$ monarquia s'havia acabat a França (el gener de 1793 el rei és guillotinat), el poble estava sobre les armes i l'Assemblea romania impotent. Un nou govern, la Convenció, va ser l'encarregat de construir la República a partir del setembre de 1792 en un context d'insurrecció interna i de guerra internacional. El 2 de juny de 1793 , però, el malestar econòmic i social provocà que els

30 Peter Mcphee, La Fevolución Francesa. 1789-1799, p. III.

3I En Donald SutherLand, «Les pendaisons populaires dans les Bouches-du-Rhône et le Sud-Est en I792 et I793", dins Michel BIARD (dir.), Les polítiques de la Terreur, 17931794, Rennes, Presses Universitaires de Rennes, 2008, pp. I4I-I54, trobem una anàlisi sobre la justícia popular i la seua relació amb les institucions centrada en el sud de França. Segons Sutherland, la violència popular no portà directament al terror en el sud-est del país. Es van donar dues condicions més: la repressió institucional contra els federalistes i les institucions revolucionàries, convertides en instruments de l'emoció popular contra els enemics.

Cercles. Revista d'História Cultural, 23 (2020), 19-55.

ISSN: 1139-0158. e-ISSN: 1699-7468. DOI: 10.1344/cercles2020.23.1009. 
sans-culottes i 80.000 guàrdies nacionals rodejaren la Convenció i expulsaren el govern girondí. Els jacobins, amb el suport i la pressió dels sans-culottes, s'apoderen de la Convenció amb la justificació que la situació d'extrema inestabilitat que patia França era responsabilitat dels girondins. A l'estiu de l'any 1793 la guerra civil es va intensificar, atès que en quaranta-nou dels vuitanta-tres departaments de França hi havia revoltes contrarevolucionàries i federalistes. ${ }^{32}, 33 \mathrm{El}$ Terror va ser la resposta a este explosiu context, un instrument per a salvar la revolució i complir les demandes dels sans-culottes. ${ }^{34}$

El terror va estar present durant tota la Revolució: la massacre dels presos de París arran de la invasió prussiana o el Terror Blanc en són exemples. Durant la Convenció i pels motius esmentats, hi ha una intensificació de les polítiques repressives, intensificació que podem situar en la repressió de la insurrecció de la Vendée, quan la Convenció estava en mans dels girondins. Serà la Convenció jacobina, amb el reclutament de quasi un milió de soldats, la que acabe

32 Marisa Linton, «Terror and politics», pp. 2-3.

33 La connexió entre centralisme i jacobinisme i entre girondins i federalisme ha estat una constant en la historiografia. Segons Michel Biard, però, les dues identificacions s'han assumit de manera acrítica. Per a una discussió sobre la qüestió del centralisme jacobí, vegeu Michel BiARD, "État jacobin et centralisation, ou la pérennité de quelques idées sur la Révolution française», Pouvoirs Locaux, desembre 2009, pp. I-5, https://sup.sorbonne-universite. $\mathrm{fr} /$ sites/default/files/public/files/Toqueville_2OIO-OI-I9_POVOIRS_LOCAUX.pdf (consultat el 3/6/2020); per a la identificació de clubs girondins i federalisme, vegeu Michel BIARD, «La machine jacobine? Un fantasme historiographique revisité à l'aune d'un exemple local: la Société populaire de Honfleur (I79I-I795)», Social and Education History, n. 4(I), febrer 20I5, pp. I-26.

34 Una part d'aquestes demandes és la creació del primer Tribunal Revolucionari el I7 d'agost de 1792 i del Tribunal Criminal Extraordinari el març de I973. Per a una anàlisi de la funció, les característiques i el funcionament quotidià del Tribunal, vegeu Alex FAIRfaX-Cholmeley, "Creating and resisting the Terror: the Paris Revolutionary Tribunal, March-June 1793", French History, n. 32, issue 2, juny 2018, pp. 203-225. La tesi de Fairfaix és que fins a la llei del 22 pradial (Io de juny de 1794) el Tribunal funcionava amb suficients garanties jurídiques i independència del poder polític. Aquest fet contrasta amb l'assumpció generalitzada per la historiografia que el tribunal era simplement aparença de legalitat. 
amb els rebels mitjançant una autèntica guerra civil i practicant una violència extraordinària. ${ }^{35}$

\section{El Terror, un producte de les circumstàncies o un producte del discurs?}

La historiografia revisionista afirma que el Terror és la concreció material de la ideologia il.lustrada que provoca el I789. Aquesta interpretació defensa una mena de pulsió misteriosa cap a la violència que necessita una justificació. En aquest sentit, la contrarevolució és l'argument que justifica la violència ${ }^{36}$ i el Terror jacobí no és sinó el 1789 amb més víctimes. ${ }^{37}$ La ideologia tindria l'estrany poder de fer abstracció de les circumstàncies concretes, «una inmanencia misteriosa que habitaría en el discurso, a veces también descrita como una sed milenarista de sangre impura». ${ }^{38}$

Aquestes tesis són insostenibles: en primer lloc, per què són més significatius els brots de violència que l'evident explosió de tolerància i de llibertat? La violència és, en realitat, insignificant respecte de l'experiència de llibertat i de tolerància. En segon lloc, el Terror fou més contundent allí on la contrarevolució fou més forta. I, en tercer lloc, les sentències polítiques per a acabar amb l'oposició disminuïren alhora que disminuïa el perill de la contrarevolució: «El terror no

35 Gonzalo Pontón, La lucha por la desigualdad. Una historia del mundo occidental en el siglo XVIII, Barcelona, Pasado y Presente, 20I6, p. 429.

36 En François Furet i Mona Ozouf, Diccionario de la Revolución Francesa, Madrid, Alianza, 1989, trobem el mot contrarevolució en l'apartat d'idees i el mot terror en l'apartat d'esdeveniments. La contrarevolució seria una idea sense referent real però derivada necessàriament de la ideologia illustrada.

37 Peter Mcphee, La Fevolución Francesa. 1789-1799, p. I79.

38 Ezequiel Sirlin, «El hilo del Terror. Quitando el halo estalinista a la Revolución Francesa», Cuadernos de Historia Contemporánea, n. 34, 20I2, pp. 343-353, p. 349.

Cercles. Revista d'História Cultural, 23 (2020), 19-55.

ISSN: 1139-0158. e-ISSN: 1699-7468. DOI: 10.1344/cercles2020.23.1009. 
puede comprenderse simplemente como la expresión de una paranoia revolucionaria». ${ }^{39} \mathrm{Tal}$ com mostra Tackett en El terror en la Revolución Francesa, fins a la fugida del rei el juny de i79I poc es parlava de conspiracions, és a dir, no podem comprendre la revolució si la reduïm a una ideologia que necessita la paranoia conspiradora per a sobreviure. ${ }^{40}$ El que fa el revisionisme és «no comprender las persistentes voces del liberalismo y la tolerancia y el modo en que el estallido de la guerra transformó las divisiones políticas en cuestiones de vida o muerte». ${ }^{4 \mathrm{I}}$ És a dir, no comprendre que les circumstàncies concretes, la guerra i les conspiracions són el que explica que les violències verbals es transformaren en violències físiques. ${ }^{42}$

Aquesta transformació és l'objecte de Tackett en Becoming a revolutionary (1996) en fer un relat de la Revolució que té com a fil conductor la transformació de la mentalitat dels diputats elegits per als Estats Generals. La conclusió és que el fet que esdevingueren revolucionaris va tenir molt a veure amb l'ansietat i amb la por deriva$\mathrm{da}$ de situacions sense referent històric, de situacions inèdites des d'un punt de vista social i polític i sobre les quals, per tant, no hi havia models d'acció: "What Tackett accomplished in this tightly focused study was to send other historians back to the drawing board: to rethink the timing of the emergence of revolutionary culture, the nature and effects of revolutionary "lived experience," and, ultima-

39 Peter Mcphee, La Fevolución Francesa. 1789-1799, p. I80.

40 Timothy Tackett, El Terror en la Revolución Francesa, pp. I49-I73.

4I Peter Mcphee, La Fevolución Francesa. 1789-1799, p. I8o.

42 En la línia de Tackett i de Linton és fonamental l'obra de David Andress, El Terror. Los años de la guillotina, Buenos Aires, Edhasa, 20II. En la seua narració dels anys del Terror i fugint, com els autors que estem analitzant, de la dicotomia entre circumstancies i ideologia, defensa que per a explicar el Terror s'han de tenir en compte multitud de factors i cal explicar-los en el context de tres guerres (externa i interna amb la contrarevolució i el federalisme) i tres crisis superposades (producció, reclutament i subministrament). Una comprensió del Terror que té en compte multitud de factors i que esmena qualsevol comprensió que referisca a una sola causa explicativa. 
tely, the psychological forces at work in the revolutionary remaking of French politics». ${ }^{43}$ Es tracta, en definitiva, de saber per què els protagonistes prengueren les decisions que prengueren, i per a explicar tal cosa (mai de manera concloent) cal fer intervenir, juntament amb les idees i les circumstàncies, qüestions com les emocions, els factors personals, les amistats, les enveges, etc. Es tracta, d'una manera o d'una altra, d'explicar els esdeveniments prenent com a punt de partida la irreductible complexitat de l'ésser humà. ${ }^{44}$

Aquest enfocament fa paleses les mancances de les interpretacions socials clàssiques i de les revisionistes. Els problemes, però, d'aquesta perspectiva de retorn al subjecte són evidents: per una banda, podem caure en l'error de projectar la nostra manera d'estar en el món als individus de fa dos-cents trenta anys; per l'altra, no tenim, ni tindrem, fonts suficients sobre les vides privades de la gent. Malgrat això, però, no hi ha més camí que intentar destriar l'individu privat de la seua imatge pública, una reconstrucció de l'individu que incloga política, ideologia i allò personal i emocional.45

És fonamental la relació públic/privat: hi havia un conflicte entre l'amistat, que es concretava en privat en els clubs, i la virtut, que era per definició enemiga d'allò privat. Si la virtut és el criteri polític, les amistats són potencialment susceptibles de ser contrarevolucionàries, sospitoses de conspiració. I és un fet que la conspiració va ser cabdal en la mentalitat dels revolucionaris i que funcionava com una

43 Sophia Rosenfeld, «Thinking about Feeling», French Historical Studies, n. 32(4), 2009, pp. 697-706, p. 699.

44 En Haim Burstin, Révolutionnaires. Pour une anthropologie politique de la Révolution française, París, Vendémiaire, 20I3, tenim una anàlisi (paral-lela en gran manera a la de Tackett) que té com a objectiu fer una caracterització sobre què és ser revolucionari, sobre el procés pel qual un individu corrent es transforma en subjecte revolucionari. Per a un comentari crític de l'obra de Burstin, vegeu Francesco Benigno, «Never the Same Again», pp. 204-2II.

45 Marisa Linton, «Terror and politics», pp. 475-479.

Cercles. Revista d'Historia Cultural, 23 (2020), 19-55.

ISSN: 1139-0158. e-ISSN: 1699-7468. DOI: 10.1344/cercles2020.23.1009. 
mena de criteri d'actuació en el qual s'havien de fonamentar les polítiques. La retòrica de la conspiració (real o imaginada) va ser un element clau en la radicalització de la Revolució. I el sentiment que la guiava, la por, va ser el motor del Terror.

Els esdeveniments, a partir de la matança de les presons de París, es desenvolupen a una velocitat $\mathrm{i}$ amb una imprevisibilitat que les tesis explicatives monofactorials resten impotents. Comprendre les accions dels revolucionaris implica tenir una teoria de la naturalesa humana $\mathrm{i}$, com que essencialment som éssers culturals, ens haurem de conformar amb temptatives, amb relats inacabats, i haurem de començar les nostres afirmacions amb un tal vegada, amb clara consciència que no hi ha explicació definitiva: «Tal vez fuera aquel miedo tan profundo y tan arraigado a la conspiración, lo que llevó a la moralización de las opciones de bandos, a la deshumanización y demonización de los oponentes y, en último término, a esa forma tóxica de las facciones que acabarían dispuestas a asumir la violencia y la eliminación física de sus rivales políticos». ${ }^{46}$ Por derivada de l'absència d'una autoritat central i del sorgiment de centres de poder local que redueixen el prestigi, la legitimitat i la confiança en les elits; por derivada de les invasions estrangeres i de les insurreccions internes; por de les elits al poble que es transforma en radicalisme i violència contra ell; por derivada de la violència del poble de París. ${ }^{47}$

46 Timothy TACKetT, El Terror en la Revolución Francesa, p. I9I.

47 Sobre la relació entre el terror institucional i la violència popular, algunes obres de referència són: Sophie WAHNICH, In defence of the terror: liberty or death in the French Revolution, Londres, Verso, 20I2. Es tracta d'un assaig filosòfic que posa l'origen i el motiu del Terror en el «serem terribles per a salvar a la gent de ser-ho» de Marat. El terror de la Convenció és la resposta pública i institucional a la violència legítima del poble. I la violència és legítima perquè la ineficiència de l'Assemblea porta el poble a exercir la seua sobirania en defensa de la revolució. La presa del palau de les Tulleries o les massacres de setembre són, en aquest sentit, actes fundacionals de la República Francesa. L'opció de detenir o reprimir el poble desapareix i a la política de la Convenció només li queda canalitzar la justícia revolucionària. La creació del primer Tribunal de la Revolució el I7 d'agost 
El resultat de tot plegat: faccions polaritzades que porten a acusacions de conspiració i que tenen com a resultat, primer, l'expulsió de la política i, després, la mort. ${ }^{48} \mathrm{Vol}$ dir això que el Terror era inevitable? Segons Linton, no. El Terror var ser una elecció. És cabdal assenyalar que la legislació terrorista no és exclusiva dels jacobins, com mostra Annie Jourdan en traure a la llum el treball del Comité de Legislació: de cap manera es pot identificar el Terror ni amb els jacobins ni amb Robespierre, que no formava part d'aquest Comité. El Terror, afirma Linton, va ser una decisió col-lectiva, un fenomen que impregnava tota la política. ${ }^{49}$ Però la pregunta es manté més enllà del qui: per què tothom trià el Terror? La resposta, com hem vist, és una mescla de circumstàncies, ideologia i sentiments que acaba, irònicament, convertint-se en el terror dels polítics, en un instrument contra els mateixos jacobins: a París els alts funcionaris i els polítics tenien molt més a témer que el poble. Els judicis de l'any II foren una farsa, una guerra entre faccions dominada pels jacobins: acusadors, testimonis contra els acusats i creadors dels relats de la virtut i la conspiració. Girondins, hebertistes, dantonistes i jacobins foren sentenciats a mort. Com s'arribà a açò?, com és que antics amics es passen els uns als altres per la guillotina? De nou, les expli-

de 1792 i del Tribunal Criminal Extraordinari el març de 1973 tindrien aquesta funció. Els líders polítics de la revolució serien mers instruments del subjecte collectiu poble; des de perspectives que arrepleguen major complexitat a l'hora de explicar la relació esmentada, a banda de les que estem analitzant, vegeu, per exemple: P. Gueniffey, La politique de la Terreur. Essai sur la violence révolutionnaire. 1789-1794, París, Fayard, 2000; Michel BIARD (ed.), Les politiques de la Terreur: 1793-1794, Rennes, PUR, 2008; Michel BIARD i Hervé Leuwers (eds.), Visages de la Terreur. L'exception politique de l'an II, París, Armand Colin, 20I4; Haim Burstin, Révolutionnaires. Pour une anthropologie politique de la Révolution Française, París, Vendémiaire, 2013, i David Andress, El Terror. Los años de la guillotina, Buenos Aires, Edhasa, 20II.

48 Timothy Tackett, El Terror en la Revolución Francesa, pp. 399-4I2.

49 Annie Jourdan, «La Convention ou l'empire des lois», La Révolution Française (en línia), desembre de 20I2, http://journals.openedition.org/lrf/730 (consultat el I6/2/2020), DOI: https://doi.org/I0.400o/lrf.730.

Cercles. Revista d'Història Cultural, 23 (2020), 19-55.

ISSN: 1139-0158. e-ISSN: 1699-7468. DOI: 10.1344/cercles2020.23.1009. 
cacions només poden ser parcials, massa generals o sense fonaments clars: "Yet there was more to it than that. The circumstances of the politicians' terror also pointed to an inner anxiety about other people's motives; the difficulty of reading what was really in someone else's heart».. ${ }^{\circ}$

La retòrica de la inautenticitat funcionà des del 1789 com a arma per a desprestigiar l'oponent polític. El problema era que, mentre que en el període constituent et jugaves, a tot estirar, la carrera política i el prestigi, durant la Convenció et jugaves el coll. ${ }^{\text {sI }}$ Durant el Terror del període jacobí, els girondins, els cordeliers i, finalment, els jacobins, foren sentenciats a mort i morts sota l'acusació de no ser homes virtuosos. La conspiració va ser «el principio organizativo más importante de la retórica revolucionaria francesa. La narrativa de la revolución estaba dominada por los complots», ${ }^{52}$ ens diu Lynn Hunt.

En definitiva, per una banda, no podem reduir les polítiques terroristes al període que anomenem Terror, sinó que ja en els inicis de la Revolució hi havia pràctiques terroristes que s'institucionalitzaren després; per altra banda, tampoc no podem, per tant, identificar-les amb els jacobins, i, per acabar, tampoc no podem comprendre-les reduint l'explicació a les idees o les condicions socials i econòmiques, sinó que necessitem tenir en compte multitud de factors irreductibles entre ells. Tot plegat ja ens indica que la imatge de Robespierre com una mena d'animal àvid de sang i de poder promocionada pel revisionisme i pels termidorians és, com veurem tot seguit, insostenible.

50 Marisa Linton, «Terror and politics», p. 480.

5I Marisa Linton, «Terror and politics», pp. 48I-482.

52 Citat per Peter Mcrhee, La Fevolución Francesa. 1789-1799, p. 179. 


\section{Robespierre}

La época fue de una insólita brutalidad, que por otra parte no se interrumpió con la muerte de Robespierre. A este respecto, Termidor no supuso una salida del Terror sino su continuación con otros protagonistas, otros vencedores y otros vencidos, un cambio de proyecto político y no un cambio de medio político. Así fue durante las décadas que siguieron. Adolphe Thiers, al reprimir a la Comuna de París en I87I, hace ejecutar a 23.000 personas en una sola Semana Sangrienta. Pese a ello, existe una calle Thiers en el distrito I6 $6^{\circ}$ de París. ${ }^{53}$

Defensor de l'abolició de la pena de mort, demòcrata des del principi en contra de la distinció entre ciutadans actius i passius, en contra de la participació de França en guerres d'agressió, a favor de l'abolició de l'esclavitud, a favor dels drets cívics de les minories religioses, apassionat defensor de la llibertat de premsa i d'expressió, ${ }^{54}$ menys que altres (pocs) a favor d'alguns drets per a les dones, ${ }^{55}$ etc., però era

53 Alexis Corbière, regidor de l'Ajuntament de París que en 201 i presenta una moció, i la perd, perquè Robespierre tinga un carrer a París. Vegi’s «Una calle para Robespierre en la capital», Le Monde, 28 de juny de 20II: http://www.sinpermiso.info/textos/una-callepara-robespierre-en-la-capital (consultat l'ı//6/2020).

54 En l'article de M. Betlem Castellà i Pujols, «Les comités des rapports et des recherches», p. 30, trobem les següents paraules de Robespierre en l'Assemblea, del i9 de març de I79I, com a reacció a la voluntat de limitar la llibertat d'expressió: «On ne peut exercer de rigueur contre personne pour des discours ; on ne peut infliger aucune peine pour des écrits. (Murmures) II n'y a pas ici de distinction à faire entre un ecclésiastique et un autre citoyen; un ecclésiastique est un citoyen et il est absurde de vouloir porter contre les ecclésiastiques une loi qu’on n'a pas encore osé porter contre tous les citoyens. Quelques importantes que soient les affaires, elles ne peuvent jamais servir de prétexte pour porter une loi générale ni particulière contre les discours ni contre les écrits, et aucun citoyen ne peut être soumis à aucune peine ni à aucune inquisition pour ses discours ni pour ses écrits. (Murmures) Des considération particulières ne doivent jamais l'emporter sur les principes de la justice et de la liberté».

55 Marisa Linton, "The choices of Maximilien Robespierre», H-France Salon (Charleston, Illinois), vol. 7, núm. I4, \#3, 2015, pp. 2-3.

Cercles. Revista d'Història Cultural, 23 (2020), 19-55.

ISSN: 1139-0158. e-ISSN: 1699-7468. DOI: 10.1344/cercles2020.23.1009. 
el cap d'un govern que havia acabat amb la monarquia i era amenaçat des de fora per una coalició de potències estrangeres $i$, des de dins, per nombroses rebel.lions populars.

\section{«Volíeu revolució sense revolució?»}

Podem partir de la pregunta següent: com és que durant la Revolució, en concret durant el Terror, Robespierre va abandonar els principis que havien guiat la seua vida política i personal? La resposta de McPhee i Linton és la següent: si van ser deixats de costat, totalment o parcial, va ser per a salvar la Revolució. La violència és un recurs necessari: no pots no usar la violència despietada si els teus enemics estan disposats a fer-ho. Robespierre era ben conscient del problema teòric que implicava comprendre la revolució i n'era, de conscient, per una qüestió evident: una revolució com aquesta era una novetat absoluta, no hi havia ni teoria en els llibres de filosofia ni exemples en els llibres d'història. No hi havia mapa, estaven obrint pas. ${ }^{56} \mathrm{La}$ teoria del govern revolucionari era tan nova com la revolució, es construïa amb la revolució. ${ }^{57}$

S'havia de tenir ben clara la diferència entre un govern constitucional i un de revolucionari legitimat per l'objectiu constitucional. El problema es pot enunciar de diverses maneres: com es pot justificar l'abolició dels drets constitucionals per a defensar el sistema constitucional?, com es pot justificar la violència com a mitjà perquè les llibertats constitucionals siguen respectades?, com es pot justificar que el camí per a materialitzar un estat de dret és la corrupció del

56 Marisa Linton, «The choices of Maximilien Robespierre», pp. 2-4.

57 Però tal com defensen historiadores com F. Gauthier, sí que hi havia una teoria de la revolució, la Declaració de Drets de l'Home i del Ciutadà. En les conclusions farem referència a aquesta idea. 
dret? Per a fer tal cosa Robespierre relaciona la virtut i el terror: la virtut és el fonament de l'acció d'un govern democràtic i popular, és a dir, un govern les decisions del qual van sempre dirigides al bé públic i mai a l'interés privat. ${ }^{58}$ Ara bé, amb la virtut n'hi ha prou quan hi ha estabilitat, quan els enemics de la humanitat, de la república democràtica, no són enlloc. Però en temps de conflicte la república necessita eines que la defensen, això és, el Terror:

Afirmo que no solo debemos exterminar a todos los rebeldes de La Vendée, sino a todos los rebeldes que luchan contra la humanidad y el pueblo francés [...] Solo hay dos bandos, el de los Hombres corruptos y el de los virtuosos. No diferenciéis a los Hombres por su fortuna o condición, sino por su naturaleza. Solo hay dos clases de hombres: los amigos de la libertad y de la igualdad, los defensores de los oprimidos, los amigos de los indigentes... y los hombres pecaminosos, ricos e injustos y la aristocracia tirana. Esa es la división existente en Francia. ${ }^{59}$

El conflicte entre teoria i pràctica, però, roman. Per molt que salvar la revolució es convertira en el principi suprem i justificatiu, el conflicte era evident. Com també sembla evident que hagué de ser traumàtic per a Robespierre convéncer-se, si és que ho va fer, que la subordinació dels seus principis era l'única solució. I ho va haver de ser, no només per l'experiència directa del Terror com a executor, sinó perquè les seues conviccions eren fruit d'una concepció del dret (derivada de la seua professió d'advocat) en defensa dels més desafa-

$58 \mathrm{El}$ concepte de virtut seria l'antítesi del concepte de cortesà, de l'individu que conspirava, cínic, corrupte, egoista. És aquesta la imatge que se'n tenia en la revolució com a contrast amb l'individu virtuós. La política de la virtut és en aquest sentit una manera de crítica i de distanciament de l'Antic Règim. Vegeu Marisa Linton, «The intellectual origins of the French Revolution", pp. I45-150.

59 Peter Mcphee, Robespierre. Una vida revolucionaria, Barcelona, Península, 20I2, p. 234 .

Cercles. Revista d'História Cultural, 23 (2020), 19-55.

ISSN: 1139-0158. e-ISSN: 1699-7468. DOI: 10.1344/cercles2020.23.1009. 
vorits. I, també, perquè defensava les seues idees amb vehemència, i sembla que sota cap tipus de pressió o temptacions de riquesa estava disposat a canviar-les, per això li deien l'incorruptible. Com afirma Linton sobre Robespierre, el sacrifici personal i de les pròpies conviccions sobre el bé comú no era simple retòrica de la virtut, «Robespierre's real strength was that he spoke the language of virtue with utter conviction». ${ }^{60}$

\section{Circumstàncies, discursos i emocions}

La idea de virtut és cabdal en la interpretació que fa Linton de l'acció de Robespierre. S'entenia de dues maneres: com una renúncia als interessos individuals en favor del bé públic i amb l'afirmació que la felicitat de debò és el producte d'ajudar els altres i de gaudir de la seua felicitat, atès que els éssers humans simpatitzem els uns amb els altres, com a membres de la mateixa espècie. La defensa d'aquesta idea de virtut era un tret definitori del govern revolucionari, era un discurs del moment. La diferència entre Robespierre i la resta era la vehemència amb què es defensava i l'afirmació que no es tractava només d'actuar com si fora virtuós, sinó de fer-ho de manera genuïna: la sospita d'hipocresia es va convertir en un lloc comú i, per a Robespierre, en una obsessió.

La república de la virtut era un sistema polític basat en la igualtat i la participació del poble; un sistema moral basat en l'ajuda mútua i la transparència política; una comunitat emocional dels ciutadans; si era necessari, s'havia de fer ús del Terror perquè la seua existència no perillara. Amb aquests estàndards morals, la possibilitat que la lluita política derivara en una lluita per la demostració de l'autenticitat havia de sorgir. Ho va fer, segurament, amb una radicalitat que nin-

6o Marisa Linton, «The choices of Maximilien Robespierre», pp. 3-4.

Cercles. Revista d'Història Cultural, 23 (2020), 19-55. ISSN: 1139-0158. e-ISSN: 1699-7468. DOI: 10.1344/cercles2020.23.1009. 
gú no podia imaginar. ${ }^{61}$ La retòrica de la conspiració definia les polítiques: entre octubre de I793 i abril de I794 havien estat executats els girondins, els hebertistes i els dantonistes. El 26 de juliol de I794, el 8 de termidor, ${ }^{62}$ Robespierre pronuncia el famós discurs en què afirma que hi ha una conspiració per a acabar amb la Revolució, sense informar, però, sobre els traïdors. Davant d'això, Fouché i altres organitzen el colp que acabarà amb Robespierre, Saint-Just, Couthon i altres dènou jacobins els dies 27 i 28 de juliol. El dia següent són executats setanta jacobins més. Molts dels executors de la sentència i els conspiradors havien estat al costat de Robespierre aplicant i defensant el Terror. La llegenda negra començava de la mà d'aquests homes com a tàctica perquè els seus propis crims foren oblidats. Robespierre es convertí en l'encarnació del diable i en el totpoderós instrument del Terror.

\section{La llegenda negra}

Responsabilitzar un individu de tot el mal evita mirar-se a un mateix, evità que la societat francesa es pensara capaç del Terror. Si Robespierre tenia alguna patologia, si el Terror va ser el seu entrete-

6I Marisa Linton, «Virtue and terror: Maximilian Robespierre on the principles of the French Revolution", dins R. Hammersley (ed.) Revolutionary moments: reading revolutionary texts, Londres, Bloomsbury, pp. 93-100, p. 2015.

62 Alguns historiadors han interpretat aquest discurs com una provocació perquè hi haguera un colp d'estat (com així va ser) i com un símptoma d'inestabilitat mental, ja que podria ser (com així va ser) un discurs suïcida. Però, com diu Colin Jones, aquestes interpretacions només es poden fer des del privilegi del coneixement dels fets posteriors al discurs, cosa que fa que les conseqüències siguen, semblen, necessàries. És indubtable, però, que la imprecisió de les denúncies desencadenà l'acció dels seus collegues amenaçats, que prepararen eixa mateixa nit el colp d'estat del dia següent.

Cercles. Revista d'História Cultural, 23 (2020), 19-55.

ISSN: 1139-0158. e-ISSN: 1699-7468. DOI: 10.1344/cercles2020.23.1009. 
niment exclusiu, podem tenir la consciència tranquil.la i, a més, evitem investigar què defensava Robespierre, amb qui i contra què. És el que hauria fet una certa historiografia que cau en el deliri del que acusa Robespierre: un genocida (Pierre Chaunu), el mestre de Mao, Pol Pot, Stalin i Hitler, un paranoic i un narcisista viciós (Eli Sagan), un tros de carn sense emocions, físicament monstruós, homosexual reprimit i misogin. Un dictador d'un estat policial, un autoritari antiliberal, un xenòfob, un contraillustrat, un megalòman paranoic i venjatiu, un feixista avant la lettre. ${ }^{63}$

La imatge d'un Robespierre àvid de sang i de violència només se sosté, com hem vist, si l'ampliem al colllectiu, amb la qual cosa centrar-se en Robespierre i convertir-lo en símbol del Terror manca de tot sentit. Així mateix, més enllà d'un context emocional infernal juntament amb la retòrica de la virtut, tal com diu McPhee, cal tenir en compte les circumstàncies materials: un programa de govern que tenia com a referent el dret natural i entrava en conflicte amb la propietat privada (qüiestió sobre la qual aprofundirem en les conclusions), les conspiracions reals i imaginàries, la guerra i la pressió popular. $^{64}$

La imatge d'un Robespierre obsessionat pel poder tampoc no sembla tenir fonament. En contra d'aquesta idea trobem infinitat de testimonis que proven la justícia del mot incorruptible: "What mat-

63 Trobem un recorregut per les representacions de Robespierre des de la mateixa Revolució en Marc Belissa i Yannick Bosc, Robespierre: la fabrication d'un mythe, París, Ellipses, 20I3. Així mateix, en la línia de la biografia de McPhee i dels treballs de Linton i Tackett, vegeu Jean-Clement Martin, Robespierre. La fabrication d'un monstre, París, Perrin, 20I6. Una anàlisi detallada que destria realitat de llegenda de manera minuciosa i posa el personatge en el seu context per a normalitzar-lo. No hi ha monstre de Robespierre, sinó una fabricació posterior que comença amb la reacció termidoriana.

64 Peter Mcrhee, «The Robespierre Problem, An Introduction», H-France Salon (Charleston, Illinois), vol. 7, issue I4, \#I, 2015, p. 9. 
tered to Robespierre far more than power was being in the right and being able to think of himself as being in the right». ${ }^{65}$ També la defensa de lleis que impedien tenir un futur polític, com l'aprovada el maig de I79I, que no permetia que els membres de l'Assemblea Constituent formaren part de la futura Assemblea Legislativa.

La imatge de dictador de Robespierre és una altra de les afirmacions insostenibles. Contra aquesta idea, els decrets del període del Terror eren fruit d'un comité que actuava com a gabinet de guerra. En els últims mesos de 1793 va emetre nou-cents vint decrets, dels quals només setanta-set eren de Robespierre i, a més, no tenien relació amb qüestions militars. Tampoc mai no es va plantejar el Terror com un sistema de govern, sinó que va ser un intent de canalitzar la fúria popular i la divisió nacional derivades de la guerra internacional i civil. El seu paper, si bé va ser important, en cap cas no es pot identificar amb el paper d'un dictador; de fet, en molts assumptes no va aconseguir el que volia. Una altra cosa és que el seu prestigi popular, la seua correspondència regular i els seus discursos, feren que es veiés popularment com el líder indiscutible. ${ }^{66}$

De tot plegat, la conclusió és clara: comprendre Robespierre, com comprendre qualsevol altre individu, depén de comprendre el context en què actua -ideològic, social, econòmic, cultural i emocional-. ${ }^{67}$ Les decisions que prengueren els revolucionaris, contràries als principis morals que havien mantingut i que molts mantenien durant el Terror, les podem explicar afirmant que és la revolució la que fa revolucionari a Robespierre i el destrueix:

65 Marisa Linton, «The choices of Maximilien Robespierre», p. 6.

66 Peter McPheE, "The Robespierre Problem», pp. 6-8.

67 Vegeu una anàlisi de la retòrica sentimentalista dels discursos de Robespierre a David Andress, «Living the Revolutionary Melodrama: Robespierre's Sensibility and the Construction of Political Commitment in the French Revolution", Representations, vol. II4, núm. I (primavera 20II), pp. IO3-I28.

Cercles. Revista d'Història Cultural, 23 (2020), 19-55.

ISSN: 1139-0158. e-ISSN: 1699-7468. DOI: 10.1344/cercles2020.23.1009. 
[...] a politics that were constantly shifting and inherently unstable and that were characterized by conflicting ideas and emotions, fervent idealism, hope, loyalty, wild excitement, suspicion, fear, betrayal, and horror. To think that Robespierre-or any other revolutionary leader-mastered the Revolution is to vastly underestimate the sheer scale of the forces that the Revolution unleashed. The Revolution made Robespierre, and the Revolution destroyed him, just as it did so many others. $^{68}$

\section{Conclusions}

[...] ¿vamos a poner fin a esta revolución o a iniciar otra? [...]. Habéis hecho iguales a todos a ojos de la ley; habéis instaurado la igualdad civil i política. Un paso más sería un acto fatal e imperdonable. Un paso adelante por la vía de la igualdad significaría la destrucción de la propiedad privada (Barnave, I5 de juliol de I79I). ${ }^{69}$

L'anàlisi que hem feta dels tres debats des d'autors del corrent sociocultural té com a tret principal la fugida de les explicacions deterministes, materialistes i idealistes, tot introduint els contextos concrets $i$, arran d'ells, la contingència i la decisió individual. Veiem dos problemes: per una banda, la tesi de les circumstàncies no ens sembla que deixe lloc a la tesi del Terror com a elecció; per altra, l'oblit del conflicte entre la llibertat republicana defensada pels jacobins i el dret de propietat.

En primer lloc, el problema que veiem en aquest plantejament, sobretot en el de Linton i Tackett (la lectura de McPhee mai perd de vista el context ideològic i social), és la pèrdua del context general,

68 Marisa Linton, "The choices of Maximilien Robespierre», p. 2.

69 Barnave, en Neil Davidson, Transformar el mundo, p. I2I. 
la sensació que les decisions de la Convenció es poden explicar reduint-les a un clima conspirador que provoca l'emoció de la por i engega el Terror. Una mena de joc macabre el premi del qual consistia a ser l'últim a tenir el cap enganxat al cos. Un joc, però, derivat de la voluntat dels actors. Així, des de la tesi de Linton que afirma que el Terror fou una elecció, que no fou l'única resposta possible a les circumstàncies, no s'entén com els revolucionaris van poder prendre decisions més o menys lliures, més o menys informades, en un context dirigit i estructurat per la por, per la sospita constant, per la conspiració real o imaginària, en definitiva, en un context que no podem deixar d'imaginar, quan llegim el relat de Linton, com una mena de paradigma del determinisme, com l'antítesi d'un espai que possibilita l'elecció lliure. En definitiva, s'hi introdueix la contingència però es dibuixa un context emocional que sembla que la fa impossible.

En segon lloc, creiem que la visió de la societat i els objectius que unes i altres faccions tenen pel que fa al tipus de comunitat política que ha de resultar de la revolució, no són tinguts en compte com caldria a l'hora d'explicar la contrarevolució i el colp que acaba amb els jacobins. Aquesta visió està determinada per part dels jacobins per la defensa de la llibertat republicana i la seua ampliació, sense cap tipus de condició, a tots els homes (ampliació que es deriva de prendre's seriosament la Declaració de 1789$).{ }^{70}$ I la llibertat republicana —és a dir, s'és lliure si no hi ha dependència d'altre— hauria portat a un xoc frontal contra els privilegis que es deriven d'un dret de propietat que no era sinó una ficció legal, una ficció que legitimava la subordinació d'una majoria a una minoria privilegiada. La Constitució

70 Florence GaUthier, «La importancia de saber por qué la Revolución Francesa no fue una revolución burguesa», https://blogs.mediapart.fr/andre-bellon/blog/3I0818/non-larevolution-francaise-nest-pas-une-revolution-bourgeoise (consultat el 27/2/2020). Ens diu per exemple, que moltes assemblees primàries, però, eren mixtes i les dones tenien dret al vot. És a dir, les dones participaren en l'elaboració de la llei..

Cercles. Revista d'Història Cultural, 23 (2020), 19-55.

ISSN: 1139-0158. e-ISSN: 1699-7468. DOI: 10.1344/cercles2020.23.1009. 
de I79I només permet el vot als homes rics ${ }^{71}$ i manté l'esclavitud. La de I795 elimina els drets socials de la de 1793 i defineix la igualtat en termes formals: la igualtat és legal, les condicions materials per a poder exercir la llibertat desapareixen. En les paraules següents del 23 de juny de 1795 de Boissy d'Anglas, president de la Convenció i decisiu en l'elaboració de la constitució del I795, ho veiem:

Deberíamos estar gobernados por los mejores de entre nosotros; los mejores son los que tienen mayor educación, y los que más interés tienen en defender las leyes; salvo raras excepciones, esta clase de hombres solo se encuentra entre aquellos que, siendo propietarios, son fieles a las tierras en las que está ubicada su propiedad... Si se concediesen derechos políticos ilimitados a hombres sin hacienda, y si tuvieran que

7I És a dir, restringeix la llibertat republicana a aquells que ja són lliures, a aquells que ja gaudeixen d'independència civil gràcies a les seues possessions. Podem veure una interpretació de la concepció que tenen els jacobins de la propietat privada en Jean-Pierre Gross, «Le liberalisme égalitaire des Jacobins», Le Monde Diplomatique, setembre 1997, www.monde-diplomatique.fr/1997/o9/GROSS/4442 (consultat el 4/6/2020). En la citació següent es resumeix la postura de l'autor: «La déclaration jacobine, affichée dans les lieux publics pendant toute la durée de la Terreur, ne vise assurément ni le nivellement absolu ni la communauté des biens. Elle s'inscrit dans le contexte d'une économie de marché précapitaliste fondée sur la propriété privée, et cherche à concilier liberté et égalité grâce au ciment de la fraternité». Trobem una magnífica narració històrica i conceptual del republicanisme en Antoni Dомѐnech, El eclipse de la fraternidad, Madrid, Akal, 2019, pp. 56-57: «Ni el mundo antiguo mediterráneo republicano, ni los revolucionarios republicanos norteamericanos y franceses de finales del xviII, habrían admitido nunca la ficción jurídica de que la "propiedad" de la fuerza de trabajo fuera una propiedad de verdad, capaz de dar independencia, existencia social autónoma y separada -libre- a quien la poseyera. [...] El orden civil de impronta napoleónica (o su equivalente funcional en los países anglosajones) rompió la lógica republicana del derecho romano, que vinculaba inextricablemente la libertad personal con las instituciones sociales capaces de dar base material a la existencia social autónoma y separada de los libres, generando una ilusión de libertad general fundada en la ficción jurídica de que todos son propietarios de algo, y por lo mismo, capaces de relaciones contractuales libres». La discussió sobre què siga la propietat és un dels eixos del llibre. 
ocupar su puesto en la asamblea legislativa, provocarían disturbios, o contribuirían a su creación sin temor a las consecuencias; impondrían o permitirían que se recaudasen impuestos fatales para el comercio y la agricultura. $^{72}$

Es veu ben clar que la ciutadania roman reduïda a una classe privilegiada: la dels propietaris. Si el projecte jacobí robespierrista volia augmentar la base ciutadana en el sentit republicà, calia qüestionar el dret a la propietat privada, això és, subordinar-lo al dret a la llibertat. En la Declaració del 24 d'abril de 1793 aquesta subordinació és evident i explícita:

Art. VII. El derecho de propiedad está limitado, como todos los demás, por la obligación de respetar los derechos del prójimo.

Art. VIII. No puede perjudicar ni la seguridad, ni la libertad, ni la existencia, ni la propiedad de nuestros semejantes.

Art. X. La sociedad está obligada a proveer la subsistencia de todos sus miembros, sea procurándoles trabajo, sea asegurando los medios de existencia a aquellos que se encuentran incapacitados para trabajar.

Art. XI. Las ayudas indispensables a quien carece de lo necesario son una deuda del que posee lo superfluo: corresponde a la ley determinar la forma en que esta deuda debe ser saldada.

Art. XII. Los ciudadanos cuyas rentas no excedan lo que es necesario para su subsistencia deben ser dispensados de contribuir a los gastos públicos. Los demás deben soportarlos progresivamente según la extensión de su fortuna. ${ }^{73}$

Tenim un conflicte entre dues maneres de comprendre la llibertat que es concreten en la contradicció entre el dret a la propietat,

72 Peter Mcrhee, La Fevolución Francesa. 1789-1799, p. I9I.

73 Maximilien Robespierre, Por la felicidad y por la libertad, Discursos, El Viejo Topo, 2005, pp. 199-200. 
que no és universal, i el dret a una vida digna, que comporta necessàriament la subordinació del primer. Com assenyala Florence Gauthier, la revolució del Io d'agost de I792 "volvió a poner en el orden del día la Declaración de Derechos y exigió un nuevo derecho humano: el derecho a la existencia y a los medios necesarios para conservarla. Los derechos económicos y sociales fueron una genuina invención de este periodo». ${ }^{74}, 75$

Aquests drets són el substitut de la propietat dels posseïdors, ${ }^{76}$ són el que legitima que puguem parlar del projecte jacobí robespierrista com un període democràtic. Els jacobins no pretenen sinó estendre a tota la societat el que des d'Aristòtil s'havia considerat llibertat, això és, eliminar la possibilitat de ser esclavitzat. Si a això hi afegim, com hem assenyalat diverses vegades al llarg del text, que les mesures terroristes ni són exclusives dels jacobins, ni tenen l’origen en el període de la revolució anomenat Terror, sinó que hi són en major o menor intensitat durant tota la revolució, si això és així, hem d'afirmar que el conflicte entre la visió democràtica i la visió liberal doctrinària ha de ser un element explicatiu clau en el colp

74 Florence Gauthier, «La importancia de saber por qué», p. 5.

75 Drets econòmics i socials que en la pràctica signifiquen la subordinació de l'economia a la moral. Subordinació que, en contra de la visió de les masses com a fenomen irracional, estaria a la base de les mobilitzacions populars que pressionen la Convenció per a adoptar polítiques basades en el dret natural que és a la base de les declaracions de drets de 1789 i de 1793 . Per a aprofundir en la qüestió de la irracionalitat o racionalitat de les multituds és aclaridor l'article de Philippe $\mathrm{MÜNCH,} \mathrm{«Les} \mathrm{foules} \mathrm{révolutionnaires,} \mathrm{la} \mathrm{vio-}$ lence populaire et l'historiographie de la révolution française: revisiter Le Bon et Tarde», Trienio, n. 67, maig 2016, pp. 165-184.

76 En temps d'Adam Smith o en els Estats Units de Jefferson, en una societat bàsicament rural, la qüestió estava clara: la llibertat depenia de tenir una propietat de terra suficient per tal de no dependre de ningú, això és, per ser lliure. Al final del segle Xviır a Europa la terra ja no podia ser l'únic element que possibilitara la llibertat republicana. Els drets socials i econòmics fan la funció que havia fet la propietat de la terra. Els qui defensen a hores d'ara la renda bàsica universal des d'una perspectiva republicana, ho fan en el sentit que diem. 
contra Robespierre i en la construcció del relat que l'identifica amb el terrorisme de 1793 i 1794 .

En definitiva, pensem que aquest enfrontament entre el liberalisme doctrinari que subordina tot el dret al dret de la propietat (i es posa així contra la democràcia) ${ }^{77} \mathrm{i}$ la idea revolucionària del dret natural que és a la base de les polítiques jacobines, és fonamental per a comprendre el procés revolucionari. Des d'aquesta perspectiva, per a explicar l'acció jacobina no en tenim prou amb una teoria de les emocions o amb la tesi de les circumstàncies, sinó que és necessari veure quines idees illustrades estaven a la base de les accions jacobines i valorar la seua importància sense caure en caricatures com les d'Israel (els jacobins eren monstres rousseaunians assedegats de sang) o en determinismes com els de Baker (la reducció de la realitat al discurs). Potser la voluntat de separar-se del revisionisme dels autors que hem analitzat ha fet que les idees (en concret, la idea de dret natural) hagen estat en part oblidades o minimitzades.

La derrota dels jacobins és la derrota del projecte republicà, la derrota de la possibilitat de constituir una comunitat política basada en el dret, la derrota de la possibilitat d'encarnar la llibertat en la història:

Igual que se suele decir que la Revolución francesa representa el triunfo de la burguesía, se podría decir que la burguesía triunfó contra la Revolución francesa. Lo mismo que se dice que el Estado moderno es el Estado burgués, podríamos decir que la burguesía enterró la posibi-

$77 \mathrm{Al}$ segle xix, el segle de l'hegemonia burgesa, el que diem és evident. La democràcia hi és precisament per a enfrontar-se a la realitat política i social. La següent declaració de drets humans és del 1948, cent cinquanta anys després de la francesa i conseqüència de dues guerres mundials.

Cercles. Revista d'Història Cultural, 23 (2020), 19-55.

ISSN: 1139-0158. e-ISSN: 1699-7468. DOI: 10.1344/cercles2020.23.1009. 
lidad de un determinado Estado moderno, precisamente ese en el que podría «imperar la ley», es decir, ser un auténtico "Estado de Derecho». En lugar de esto tenemos una dictadura económica que a veces, y en determinados momentos y lugares suficientemente privilegiados, ha podido disfrazarse con los ropajes del derecho y del parlamentarismo. $^{78}$

78 Carlos Fernández Liria, En defensa del populismo, Madrid, Catarata, 20i6, pp. $9 \mathrm{I}-92$.

Cercles. Revista d'Història Cultural, 23 (2020), 19-55. ISSN: 1139-0158. e-ISSN: 1699-7468. DOI: 10.1344/cercles2020.23.1009. 